\title{
Seroprevalence of Zika and Dengue Virus Antibodies among Migrant Workers, Taiwan, 2017
}

\section{Guey Chuen Perng, Tzu-Chuan Ho, Hsin-I Shih, Chia-Hua Lee, Pei-Wen Huang, Chih-Huan Chung, Nai-Ying Ko, Wen-Chien Ko, Yu-Wen Chien}

A serosurvey of 600 workers newly arrived in Taiwan from 4 Southeast Asia countries showed that $18(3 \%)$ were positive for Zika virus IgM; 6 (1\%) fulfilled the World Health Organization criteria for laboratory-confirmed recent Zika virus infection. The incidence of Zika virus infection in Southeast Asia might be underestimated.

A pproximately 690,000 migrant workers live in Taiwan; most are from 4 countries in Southeast Asia: Indonesia, the Philippines, Thailand, and Vietnam. Although these migrants are valuable to the workforce, they may also bring the risk of spreading mosquitoborne diseases. Most imported cases of Zika virus and dengue virus (DENV) infections in Taiwan come from Southeast Asia. Although screening for fever at international airports was implemented in Taiwan in 2003 (1), most Zika virus and DENV infections are inapparent and cannot be detected.

For assessing the true disease burden of flavivirus infections, seroprevalence studies are effective. Recently, several serosurveys of Zika virus infections were conducted in Africa, Oceania, Latin America, and the Caribbean (2). Although small outbreaks of Zika virus infection have been reported in Singapore, Vietnam, and Thailand (3-5), seroprevalence in Southeast Asia countries remains largely unknown. To estimate the incidence of Zika virus and DENV infections in Southeast Asia and to evaluate the risk of importing these viruses into Taiwan, we investigated seroprevalence of IgM and IgG against these viruses among newly arrived migrant workers in Taiwan.

Author affiliations: National Cheng Kung University College of Medicine, Tainan, Taiwan (G.C. Perng, T.-C. Ho, H.-I. Shih, C.-H. Lee, P.-W. Huang, N.-Y. Ko, W.-C. Ko, Y.-W. Chien); National Cheng Kung University Hospital, Tainan (H.-I. Shih, N.-Y. Ko, W.-C. Ko, Y.-W. Chien); Kuo General Hospital, Tainan (C.-H. Chung)

DOI: https://doi.org/10.3201/eid2504.181449

\section{The Study}

Migrant workers are required by law to undergo preemployment health examinations within 3 days of arrival in Taiwan. For this study, we recruited 600 newly arrived migrant workers from Indonesia, the Philippines, Thailand, and Vietnam (150 workers from each country) who received preemployment examinations at a regional hospital in Tainan, Taiwan, during June-August 2017. Workers who were $>20$ years of age and willing to participate were eligible without specific exclusion criteria. We used commercial ELISAs (https://focusdx.com) to test for IgM and IgG against dengue virus, anti-Zika virus IgG ELISA (Euroimmun AG, https://www.euroimmun.com) to test for IgG against Zika virus, and InBios Zika Detect IgM Capture ELISA (http://www.inbios.com) to test for IgM against Zika virus (because this assay seems to have higher sensitivity) (6). All tests were performed and interpreted according to manufacturers' instructions. We performed plaque reduction neutralization tests (PRNTs) on a subgroup of samples to detect neutralizing antibodies against 4 DENV serotypes (DENV-1, strain Hawaii; DENV-2, strain 16681; DENV-3, strain H87; DENV-4, strain H241) and 2 Zika virus strains (strain MR766 and 1 clinical isolate from a patient who acquired infection in Thailand). We calculated titers required to reduce dengue and Zika viral plaques by $50 \%\left(\mathrm{PRNT}_{50}\right)$ and $90 \%\left(\mathrm{PRNT}_{90}\right)($ Appendix, https:// wwwnc.cdc.gov/EID/article/25/4/18-1449-App1.pdf). For persons positive for Zika virus IgM, we used the interim case definition of laboratory-confirmed cases of recent Zika virus infection defined by the World Health Organization to see whether they fulfilled these criteria: $\operatorname{IgM}$ antibody against ZIKV positive and $\mathrm{PRNT}_{90}$ for ZIKV with titer $\geq 20$ and ZIKV PRNT ${ }_{90}$ titer ratio $\geq 4$ compared to other flaviviruses (7). This study was approved by the institutional review board of National Cheng Kung University Hospital (approval no. A-ER-106-045).

Most migrant workers were young adults 20-39 years of age (Appendix Table 1). Of the 600 workers, 18 (3.0\%) were positive for Zika virus IgM and 233 (38.8\%) were positive for Zika virus IgG. Only $3(0.5 \%)$ workers had detectable DENV IgM, but 484 (80.7\%) had DENV IgG. Seroprevalence of IgG against Zika virus and DENV was much lower in Vietnam than in the other 3 countries (Appendix Tables 2, 3). 
Table 1. Zika virus and DENV serostatus for 600 migrant workers from Southeast Asia, Taiwan, 2017*

\begin{tabular}{|c|c|c|c|c|c|}
\hline \multirow[b]{3}{*}{ Serostatus } & \multicolumn{5}{|c|}{ No. (\%) workers } \\
\hline & \multicolumn{2}{|c|}{ Zika virus IgG+ } & \multicolumn{2}{|c|}{ Zika virus IgG- } & \multirow[b]{2}{*}{ Total } \\
\hline & Zika virus IgM+ & Zika virus IgM- & Zika virus IgM+ & Zika virus IgM- & \\
\hline \multicolumn{6}{|l|}{ DENV IgG+ } \\
\hline DENV IgM+ & 0 & $3(0.5)$ & 0 & 0 & $3(0.5)$ \\
\hline DENV IgM- & $11(1.8)$ & $213(35.5)$ & $6(1.0)$ & $251(41.8)$ & $481(80.2)$ \\
\hline \multicolumn{6}{|l|}{ DENV IgG- } \\
\hline DENV IgM+ & 0 & 0 & 0 & 0 & 0 \\
\hline DENV IgM- & 0 & $6(1.0)$ & $1(0.2)$ & 109 (18.2) & $116(19.3)$ \\
\hline Total & $11(1.8)$ & $222(37.0)$ & $7(1.2)$ & $360(60.0)$ & $600(100)$ \\
\hline
\end{tabular}

Among all workers, 227 (37.8\%) had IgG against both Zika virus and DENV, $6(1.0 \%)$ had only Zika virus IgG, 257 (42.8\%) had only DENV IgG, and 110 (18.3\%) were negative for both (Table 1). All 18 workers positive for Zika virus IgM were negative for DENV IgM, indicating that false-positive results from cross-reactivity with DENV IgM or polyclonal B cell stimulation were unlikely. We found that $6(1 \%)$ workers positive for Zika virus IgM had Zika virus PRNT $_{90}$ titers $\geq 20$, and their Zika virus $\mathrm{PRNT}_{90}$ titer ratio was $\geq 4$ compared with that of 4 serotypes of DENV (Table 2; Appendix Table 4). Although we did not perform PRNT for flaviviruses other than Zika virus and DENV, we assumed that these 6 workers fulfilled the World Health Organization criteria of confirmed Zika virus infection. All 3 workers with positive DENV IgM had detectable $\mathrm{PRNT}_{50}$ and $\mathrm{PRNT}_{90}$ titers against single or multiple DENV serotypes; thus, the positive ELISA results for DENV IgM were considered true positives. Among 6 participants with positive Zika virus IgG but negative DENV IgG, 5 had a high $\mathrm{PRNT}_{50}$ titer against Zika virus (Appendix Table 4).

\section{Conclusions}

Zika virus IgM persists for $\approx 12$ weeks $(8)$; therefore, our results suggest that $1 \%$ of the workers had confirmed Zika virus infection within 3 months before blood collection, implying that the incidence of Zika virus infection in Southeast Asia might be severely underestimated. The median duration of viremia is 2 weeks (9); thus, some workers might have entered Taiwan during their viremia period and had the potential to spread Zika virus through Aedes mosquitoes in Taiwan. In addition, Zika virus can be detected in semen up to 6 months after symptom onset (10); thus, Zika virus transmission through sexual contact with these workers, who are at a sexually active age, is also possible. Furthermore, 3 female workers with confirmed Zika virus infection were of childbearing age, raising concerns about the risk for congenital infection.

The infectiousness of persons with asymptomatic Zika virus infection remains unknown. However, a recent study of DENV showed that asymptomatic persons could infect mosquitoes despite their lower average level of viremia (11). A recent modeling analysis estimated that $84 \%$ of DENV transmission is attributable to persons with inapparent infections because these persons are more mobile (12). If the infection characteristics of Zika virus are similar to those of DENV, the ability of fever screening programs at international airports and ports to prevent importation of Zika virus from migrant workers and travelers will be limited.

In this study, we may have overestimated Zika virus IgG seroprevalence (38.8\%) because of false positivity resulting from cross-reactivity; nevertheless, the observed

Table 2. Serostatus and neutralizing antibody titers for Zika virus and DENV among 11 migrant workers from Southeast Asia who were IgM and IgG positive for Zika virus, Taiwan, $2017^{*}$

\begin{tabular}{|c|c|c|c|c|c|c|c|c|c|c|}
\hline \multirow{3}{*}{$\begin{array}{l}\text { Worker no., age, } \\
\text { y/sex }\end{array}$} & \multicolumn{4}{|c|}{ ELISA } & \multirow{2}{*}{\multicolumn{6}{|c|}{ 90\% PRNT titer }} \\
\hline & \multirow{2}{*}{$\begin{array}{l}\text { Zika virus } \\
\text { IgM }\end{array}$} & \multirow{2}{*}{$\begin{array}{c}\text { Zika virus } \\
\lg G\end{array}$} & \multirow{2}{*}{$\begin{array}{l}\text { DENV } \\
\text { IgM }\end{array}$} & \multirow{2}{*}{$\begin{array}{l}\text { DENV } \\
\lg G\end{array}$} & & & & & & \\
\hline & & & & & DENV-1 & DENV-2 & DENV-3 & DENV-4 & Thai & MR766 \\
\hline ID01, 21/F† & + & + & - & + & 10 & 10 & $<10$ & $<10$ & 149 & 399 \\
\hline ID02, 37/F & + & + & - & + & 609 & 1,401 & 40 & $<10$ & 10 & $<10$ \\
\hline ID03, 28/M & + & + & - & + & 138 & 505 & 11 & 149 & 438 & $<10$ \\
\hline VN01, 34/M† & + & + & - & + & $<10$ & 40 & $<10$ & $<10$ & 40 & 160 \\
\hline $\mathrm{PH} 01,28 / \mathrm{F}+$ & + & + & - & + & 124 & 440 & 147 & $<10$ & 1486 & $>2,560$ \\
\hline $\mathrm{PH} 02,24 / \mathrm{M} \dagger$ & + & + & - & + & $<10$ & 10 & $<10$ & $<10$ & 227 & 639 \\
\hline $\mathrm{PH} 03,24 / \mathrm{F}+$ & + & + & - & + & $<10$ & $<10$ & $<10$ & $<10$ & 800 & 1279 \\
\hline TH01, 42/M & + & + & - & + & $<10$ & 40 & $<10$ & $<10$ & 107 & 143 \\
\hline $\mathrm{TH} 02,46 / \mathrm{M} \dagger$ & + & + & - & + & $<10$ & 513 & $<10$ & $<10$ & 593 & $>2,560$ \\
\hline $\mathrm{TH} 03,43 / \mathrm{F}$ & + & + & - & + & 405 & 310 & 40 & 40 & 10 & 1,215 \\
\hline $\mathrm{TH} 04,31 / \mathrm{M}$ & + & + & - & + & $>2,560$ & 1,360 & 1,600 & 10 & 1,468 & 1,599 \\
\hline
\end{tabular}

*DENV, dengue virus; DENV-1-4, DENV serotypes 1-4; MR766, African Zika virus strain MR766; PRNT, plaque reduction neutralization test; Thai, 1 Zika virus isolate from a worker with an imported case acquired in Thailand.

†Six persons positive for Zika virus IgM fulfilled the criteria for laboratory confirmation of recent Zika virus infection adopted with definition according to the World Health Organization (7). 
seroprevalence is comparable with that in Martinique $(42.2 \%)$ and French Polynesia (49\%) but lower than that in Brazil (63.3\%) and Micronesia (73\%) (2). It remains unclear why only very few cases of Zika virus-related microcephaly have been reported in Southeast Asia (13) despite such high seroprevalence. Possible explanations are differences in virus strains, differences in host factors, and limitations of the surveillance system (14).

To our surprise, seroprevalence of DENV IgM was lower than that of Zika virus IgM. In DENV-hyperendemic countries, children may have been exposed to multiple DENV serotypes and then acquired immunity; therefore, the incidence of dengue in adults is relatively low. Also of note, we observed much lower seroprevalences of Zika virus and DENV among workers in Taiwan from Vietnam, which may be because most of these workers originally came from rural areas in subtropical northern Vietnam, where the population density and climate are not suitable for establishing endemic transmission cycles of mosquitoborne viruses (15).

Our finding that $1 \%$ of migrant workers from Southeast Asia had laboratory-confirmed recent Zika virus infection suggests that the incidence of Zika virus infection in this region is underestimated. Given the convenience of flight for global travel, the risk for international dissemination of Zika virus by workers and travelers originating from Southeast Asia cannot be neglected.

This work was partially supported by the Taiwan National Health Research Institutes (grant no. NHRI-106A1MRCO-0517171 to Y.-W.C.), Ministry of Health and Welfare (MOHW104-CDC-C-114-114901-H105002 to G.C.P.), Taiwan Ministry of Science and Technology (MOST 106-2320-B-006-036 to Y.-W.C. and MOST-105-2321-B006-024 to G.C.P.), and National Cheng Kung University Hospital (NCKUH-10702020 to Y.-W.C.).

\section{About the Author}

Dr. Perng is a professor at the Department of Microbiology and Immunology, College of Medicine, National Cheng Kung University, Tainan, Taiwan. His primary research interests are the role and fate of stem and progenitor cells during the acute stages of DENV infection, their development in asymptomatic and persistent DENV infection, and the epidemiology of Zika virus and DENV infections.

\section{References}

1. Kuan MM, Chang FY. Airport sentinel surveillance and entry quarantine for dengue infections following a fever screening program in Taiwan. BMC Infect Dis. 2012;12:182. http://dx.doi.org/10.1186/1471-2334-12-182
2. Fritzell C, Rousset D, Adde A, Kazanji M, Van Kerkhove MD, Flamand C. Current challenges and implications for dengue, chikungunya and Zika seroprevalence studies worldwide: a scoping review. PLoS Negl Trop Dis. 2018;12:e0006533. http://dx.doi.org/10.1371/journal.pntd.0006533

3. Ho ZJM, Hapuarachchi HC, Barkham T, Chow A, Ng LC, Lee JMV, et al.; Singapore Zika Study Group. Outbreak of Zika virus infection in Singapore: an epidemiological, entomological, virological, and clinical analysis. Lancet Infect Dis. 2017; 17:813-21. http://dx.doi.org/10.1016/S1473-3099(17)30249-9

4. Chu DT, Ngoc VTN, Tao Y. Zika virus infection in Vietnam: current epidemic, strain origin, spreading risk, and perspective. Eur J Clin Microbiol Infect Dis. 2017;36:2041-2. http://dx.doi.org/ 10.1007/s10096-017-3030-8

5. Khongwichit S, Wikan N, Auewarakul P, Smith DR. Zika virus in Thailand. Microbes Infect. 2018;20:670-5.

6. Granger D, Hilgart H, Misner L, Christensen J, Bistodeau S, Palm J, et al. Serologic testing for Zika virus: comparison of three Zika virus IgM-screening enzyme-linked immunosorbent assays and initial laboratory experiences. J Clin Microbiol. 2017; 55:2127-36. http://dx.doi.org/10.1128/JCM.00580-17

7. Ward MJ, Alger J, Berrueta M, Bock H, Buekens P, Cafferata ML, et al. Zika virus and the World Health Organization criteria for determining recent infection using plaque reduction neutralization testing. Am J Trop Med Hyg. 2018;99:780-2. http://dx.doi.org/ 10.4269/ajtmh.18-0237

8. Landry ML, St George K. Laboratory diagnosis of Zika virus infection. Arch Pathol Lab Med. 2017;141:60-7. http://dx.doi.org/ 10.5858/arpa.2016-0406-SA

9. Paz-Bailey G, Rosenberg ES, Doyle K, Munoz-Jordan J, Santiago GA, Klein L, et al. Persistence of Zika virus in body fluids-preliminary report. N Engl J Med. 2017;379. h ttp://dx.doi.org/10.1056/NEJMoa1613108

10. Nicastri E, Castilletti C, Liuzzi G, Iannetta M, Capobianchi MR, Ippolito G. Persistent detection of Zika virus RNA in semen for six months after symptom onset in a traveller returning from Haiti to Italy, February 2016. Euro Surveill. 2016;21:pii:30314. http://dx.doi.org/10.2807/1560-7917.ES.2016.21.32.30314

11. Duong V, Lambrechts L, Paul RE, Ly S, Lay RS, Long KC, et al. Asymptomatic humans transmit dengue virus to mosquitoes. Proc Natl Acad Sci U S A. 2015;112:14688-93. http://dx.doi.org/ 10.1073/pnas.1508114112

12. Ten Bosch QA, Clapham HE, Lambrechts L, Duong V, Buchy P, Althouse BM, et al. Contributions from the silent majority dominate dengue virus transmission. PLoS Pathog. 2018;14:e1006965. http://dx.doi.org/10.1371/journal.ppat.1006965

13. Wongsurawat T, Athipanyasilp N, Jenjaroenpun P, Jun SR, Kaewnapan B, Wassenaar TM, et al. Case of microcephaly after congenital infection with Asian lineage Zika virus, Thailand. Emerg Infect Dis. 2018;24:1758-61. http://dx.doi.org/10.3201/ eid2409.180416

14. Lim SK, Lim JK, Yoon IK. An update on Zika virus in Asia. Infect Chemother. 2017;49:91-100. http://dx.doi.org/10.3947/ ic. 2017.49.2.91

15. Rabaa MA, Simmons CP, Fox A, Le MQ, Nguyen TTT, Le HY, et al. Dengue virus in sub-tropical northern and central Viet Nam: population immunity and climate shape patterns of viral invasion and maintenance. PLoS Negl Trop Dis. 2013;7:e2581. http://dx.doi.org/10.1371/journal.pntd.0002581

Address for correspondence: Yu-Wen Chien, Department of Public Health, College of Medicine, National Cheng Kung University, No. 1, University Rd, Tainan 70101, Taiwan; email: yuwenchien@mail.ncku.edu.tw 